Article

\title{
Amorphous-Nanocrystalline Composites Prepared by High-Pressure Torsion
}

\author{
Inga Permyakova ${ }^{1, *}$ and Alex Glezer ${ }^{1,2}$ \\ 1 Scientific Center of Metal Science and Metal Physics, Bardin Central Research Institute of Ferrous Metallurgy, \\ 105005 Moscow, Russia; a.glezer@mail.ru \\ 2 Department of Physical Materials, National University of Science and Technology “MISIS", 119049 Moscow, \\ Russia \\ * Correspondence: inga_perm@mail.ru; Tel.: +7-495-777-93-50
}

Received: 23 February 2020; Accepted: 14 April 2020; Published: 15 April 2020

check for updates

\begin{abstract}
This article presents systematic studies of the preparation method and the specific features of the changes in the structure and properties of amorphous-nanocrystalline composites formed from melt-quenched ribbons of iron- and cobalt-based amorphous alloys and the $\mathrm{Cu}-\mathrm{Nb}$ crystalline nanolaminates by severe plastic deformation by torsion in the Bridgeman chamber at high quasi-hydrostatic pressure.
\end{abstract}

Keywords: composite; amorphous alloy; nanolaminate; severe plastic deformation; high-pressure torsion; hardness; crack resistance

\section{Introduction}

The development of the basic principles for creating new composite materials is undoubtedly an important task of modern materials science. The demand for such materials is due to the possibility of combining enhanced mechanical properties (strength, wear resistance, crack resistance, stiffness, heat resistance and fatigue limit) [1-3].

Along with natural composites (mollusk shells, bones, wood), there are man-made artificial composites based on polymer, metal and ceramic matrices reinforced with fibers or filled with disperse particles. Such variety allows one to permanently expand the application field for composite materials.

Comprehensive studies have shown that enhanced mechanical properties can be achieved in multilayer composite systems consisting of amorphous and crystalline materials [4-9]. In addition, metallic materials with discrete structure constituents of nanoscale range can combine increased ductility with sufficiently high strength characteristics. This differs amorphous-nanocrystalline composites and advanced nanocrystalline materials from conventional structural materials produced by conventional technologies. Moreover, the controlled transformation of amorphous into nanocrystalline state makes it possible to successfully manage the functional properties of amorphous-nanocrystalline composites [10-13]. There is a well-known Ulitovsky-Taylor method for manufacturing one-dimensional composite material consisting of a high-strength magnetically soft metal base with an amorphous and/or nanocrystalline structure and an outer glass shell [14,15]. Another way to obtain amorphous-nanocrystalline composites is to decrease the critical rate of melt cooling upon manufacture of amorphous alloys (AA) by melt spinning method [16]. Heat treatment of AA at controlled temperature and time parameters initiates the nucleation and growth of nanocrystals, i.e., the formation of a composite material with an amorphous matrix [17-19]. It is possible to modify the AA surface by laser for the manufacture of "sandwich" amorphous-nanocrystalline composites and gradient structures with amorphous-nanocrystalline components [20-22]. The composite consisting 
of an amorphous phase with a nanocrystalline filler can surpass fully amorphous or fully crystalline analogs in the combination of properties [23-26].

As is known, high-pressure torsion (HPT) allows one to create new structure states by the consolidation of small fractions, due to the occurrence of the "crystalline-amorphous" phase transitions in the material [27-29]. In the framework of the present work, the idea arose to use the possibilities of severe plastic deformation (SPD) in a Bridgman chamber for the preparation of layered amorphous-nanocrystalline composites. We used two fundamentally different methodological techniques (Figure 1):

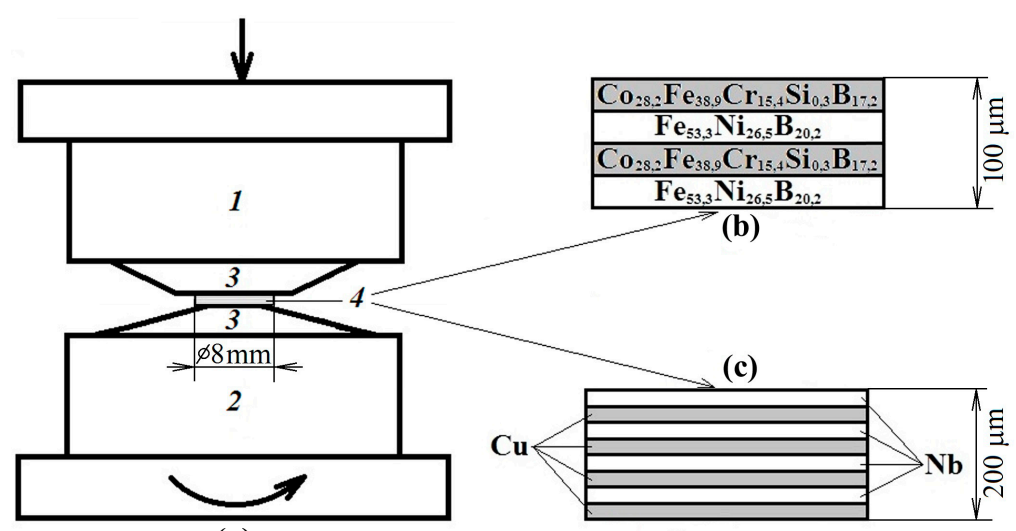

(a)

Figure 1. (a) Severe plastic deformation (SPD) scheme for the composite preparation: Bridgman chamber consisting of immobile 1 and movable 2 anvils, carbide inserts 3, sample 4 of alternating amorphous alloys (AA) ribbons (b) or the $\mathrm{Cu}-\mathrm{Nb}$ nanolaminate (c).

(1) HPT consolidation of AA melt spun ribbons differing in chemical compositions and mechanical properties [30];

(2) the use of Bridgman chamber for deformation processing of nanocrystalline $\mathrm{Cu}-\mathrm{Nb}$ laminates prepared by multiple pack rolling (MPR) [31].

$\mathrm{AA}$, due to the presence of a homogeneous structure and the absence of defects (dislocations and grain boundaries), demonstrate a higher level of mechanical properties that exceeds the level of properties achieved in the crystalline alloys. However, these materials have a serious flaw-the absence of tensile plasticity and low plastic deformation under compressive loads-which makes them prone to brittle fracture, and, accordingly, greatly limits their possible application. Structure changing during crystallization is an important aspect of AA research, since one of the ways to increase the ductility of AA is the formation of composite structure "glass-crystal".

Ternary AA of the Fe-Ni-B system (for example, $\mathrm{Fe}_{58} \mathrm{Ni}_{25} \mathrm{~B}_{17}, \mathrm{Fe}_{53.3} \mathrm{Ni}_{26.5} \mathrm{~B}_{20.2}, \mathrm{Fe}_{50} \mathrm{Ni}_{33} \mathrm{~B}_{17}$ ) are model alloys. External actions on the Fe-Ni-B AA cause precipitation of a Fe-Ni nanocrystalline phase, which can vary in crystal lattice types (BCC, FCC) depending on the ratio between the iron and nickel concentrations. Thus, it possible to establish the effect of the type crystal lattice of nanocrystals on the mechanical behavior of materials with an amorphous-nanocrystalline structure. In addition, partial crystallization can favor changes in their soft magnetic characteristics.

The Co-Fe-Cr-Si-B AA is related to corrosion resistant materials and exhibits a high electrical resistivity, low magnetization-reversal loss over a wide frequency range, low coercive force and resistance to impacts and vibrations. The high-cobalt amorphous alloys are characterized by near-zero saturation magnetostriction $\left(\lambda_{s} \leq 10^{-7}\right)$ and very high magnetic permeability. For this reason, such AA show promise as materials for magnetic shields [23].

Multilayer $\mathrm{Cu}-\mathrm{Nb}$ laminates with nanoscale layer thicknesses are typical representatives of nanostructured composite materials with a unique combination of properties: good ductility, high electrical conductivity of copper and superconductivity of niobium. The combination of the 
copper-niobium system is demanded, and is actively used in the manufacture of microwires in resonant power transmission systems, inductors for magnetic pulse stamping and welding, foils in electronics for flexible printed circuits; in large magnetic systems at 50-100 T and in high-field cryogenic synchronizers of industrial frequency.

\section{Materials and Methods}

In the first case, the $\mathrm{Fe}_{53.3} \mathrm{Ni}_{26.5} \mathrm{~B}_{20.2}$ and $\mathrm{Co}_{28.2} \mathrm{Fe}_{38.9} \mathrm{Cr}_{15.4} \mathrm{Si}_{0.3} \mathrm{~B}_{17.2}$ (at. \%) melt quenched AA ribbons $25 \mu \mathrm{m}$ thick were taken as objects of the study and composite constituents (Figure $1 \mathrm{~b}$ ). The total thickness of the initial sample (before HPT), consisting of 4 alternating layers of ribbons of AA, was $100 \mu \mathrm{m}$, respectively.

In this case, SPD was performed by $\mathrm{HPT}(P=6 \mathrm{GPa}, v=1 \mathrm{rpm})$ in a Bridgman chamber to different degrees of deformation preset by varying the number of revolutions $(N)$ of rotating anvil from $1 / 2$ to 9. Before HPT, the AA ribbons were cut into fragments $1 \mathrm{~cm} \times 1 \mathrm{~cm}$ in size, and then the fragments were piled in groups of four and deformed in the Bridgman chamber to a given number of revolutions. Ethanol was applied to the degreasing of the ribbons surface before the HPT. In such a way, the deformation-induced disk samples were formed from each alloy and similar composite samples were formed from alternating $\mathrm{Fe}_{53.3} \mathrm{Ni}_{26.5} \mathrm{~B}_{20.2}$ and $\mathrm{Co}_{28.2} \mathrm{Fe}_{38.9} \mathrm{Cr}_{15.4} \mathrm{Si}_{0.3} \mathrm{~B}_{17.2} \mathrm{AA}$ layers. The amorphous and crystalline phases in the alloys and composites were identified by transmission electron microscopy (TEM) with a JEM 1400 microscope (Jeol Ltd., Tokyo, Japan) at an accelerating voltage of $120 \mathrm{kV}$ and by X-ray diffraction (XRD) analysis with an Ultima IV multifunctional diffractometer (Rigaku Corp, Tokyo, Japan) with $\mathrm{CoK}_{\alpha}$ radiation. The microhardness of the disk samples was measured at 1/2 radius by indentation with a Vickers pyramid using a MHT-3M microhardness tester (Lomo, St. Petersburg, Russia) at a load of $0.40 \mathrm{~N}$ by a standard technique. $K_{1 c}$ values were calculated by the formula:

$$
K_{1 c}=A(E / H V)^{1 / 2} P / C^{3 / 2}
$$

where $A=0.016$ is the calibration coefficient of proportionality for thin ribbons of amorphous alloys; $E$ is Young's modulus measured by dynamic indentation methods; $H V$ is Vickers microhardness; $P$ is the critical load for the appearance of radial cracks in the process of local loading of samples of amorphous alloys; $C$ is the average length of cracks [32,33]. The indentation of amorphous alloys was carried out only in the plane of the sample.

The magnetic properties were measured at room temperature in fields of up to 20 kOe with a VSM 250 vibrating-sample magnetometer (Xiamen Dexing Magnet Tech. Co., Ltd., Xiamen, China). Measured hysteresis loops were used to determine the saturation magnetization $\left(\sigma_{s}\right)$ and the coercive force $\left(H_{C}\right)$.

In the second case, the initial $\mathrm{Cu}-\mathrm{Nb}$ nanolaminates (Figure 1c) were produced by a series of the following sequential operations making up technological cycle of the MPR process [34,35]: assembling a pack with a given number of layers, rolling of the pack in vacuum at a temperature of $750-800{ }^{\circ} \mathrm{C}$, and then cold rolling in air to a thickness equal to that of a single initial layer of the composite. This procedure is more efficient than that reported in [36,37]. In addition, the holding time of the compacted pack at high temperature within this technological scheme is much shorter than that is in the case of diffusion welding. The initial plates of $50 \mathrm{~mm} \times 100 \mathrm{~mm}$ in area and $0.35 \mathrm{~mm}$ thick were assembled into a pack of 32 alternating copper and niobium layers. The total degrees of reduction were $40 \%$ upon vacuum rolling and $10 \%$ upon cold rolling.

The prepared nanolaminates were subjected to HPT in Bridgman anvils at $P=4$ GPa to $1 / 2-4$ revolutions. Before $\mathrm{HPT}$, the samples were cut to fragments of $1 \mathrm{~cm} \times 1 \mathrm{~cm}$ in area. The thickness of the $\mathrm{Cu}-\mathrm{Nb}$ laminate samples (before HPT) was $200 \mu \mathrm{m}$ (Figure 1c).

The structure changes in the samples were examined by the methods of transmission electron microscopy (TEM) and scanning electron microscopy (SEM) with a JEM 2100 microscope (Jeol Ltd., Tokyo, Japan) equipped with a BSE detector. The chemical composition of the elements and their 
distribution in the specimens subjected to SPD were determined by the methods of bright-field and dark-field scanning transmission electron microscopy (BF-STEM/DF-STEM) and energy dispersive X-ray spectroscopy (EDS) with a JEM ARM-200F cold-emission microscope (Jeol Ltd., Tokyo, Japan) equipped with a CENTURIO EDX E-Max EDS detector (Jeol Ltd., Tokyo, Japan). The foils for the high-resolution electron-microscopic examinations were prepared from cross-section samples by a standard procedure [38]. The XRD spectra were obtained with an Ultima IV multifunction diffractometer (Rigaku Corp, Tokyo, Japan), using copper emission and a $K_{\beta}$ filter (Ni). The Vickers hardness was measured in the half-radius region of consolidated disk-shaped specimens using a standard procedure with a microhardness tester in three dimensions (3D). For this purpose, the disk-shaped nanocomposite samples were cut in four equal segments, and their flat surfaces and two orthogonally related butt-ends after polishing were subjected to indentation.

\section{Results and Discussion}

\subsection{Amorphous-Nanocrystalline Composites Prepared by Consolidation of Two Amorphous Alloys upon HPT}

At the initial SPD stages, the consolidation of AA ribbon samples of the same composition, $\mathrm{Fe}_{53.3} \mathrm{Ni}_{26.5} \mathrm{~B}_{20.2}$ or $\mathrm{Co}_{28.2} \mathrm{Fe}_{38.9} \mathrm{Cr}_{15.4} \mathrm{Si}_{0.3} \mathrm{~B}_{17.2}$, is difficult because of weak adhesion between the layers. Monolithic samples without delamination into individual ribbon components were obtained only after HPT to $N=3$ revolutions. By contrast, the composites consisting of alternating $\mathrm{Fe}_{53.3} \mathrm{Ni}_{26.5} \mathrm{~B}_{20.2}$ and $\mathrm{Co}_{28.2} \mathrm{Fe}_{38.9} \mathrm{Cr}_{15.4} \mathrm{Si}_{0.3} \mathrm{~B}_{17.2} \mathrm{AA}$ ribbons exhibit adequate adhesiveness of the layers starting from $N=1$.

According to the XRD data for the $\mathrm{Fe}_{53.3} \mathrm{Ni}_{26.5} \mathrm{~B}_{20.2} \mathrm{AA}$, no clear changes (except for a decrease in the intensity of peak corresponding to the first halo) in the XRD patterns are observed as the number of revolution increases (Figure $2 \mathrm{a}$ ). The $\mathrm{Co}_{28.2} \mathrm{Fe}_{38.9} \mathrm{Cr}_{15.4} \mathrm{Si}_{0.3} \mathrm{~B}_{17.2}$ AA subjected to HPT to $N=2$ exhibits the onset of crystallization (Figure $2 \mathrm{~b}$ ), where the volume fraction of crystalline phase is $V_{c r} \approx 10 \%$. The crystallite peaks disappear at $N=3$ and appear again at $N=5$, at which $V_{c r} \approx 16 \%$.

(a)

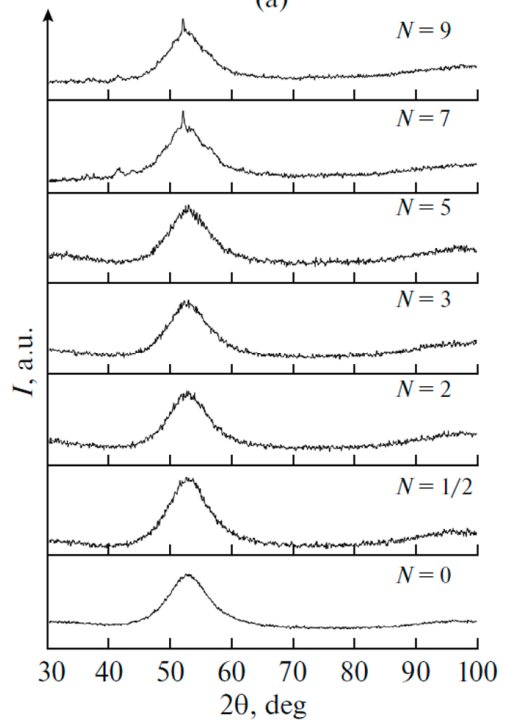

(b)

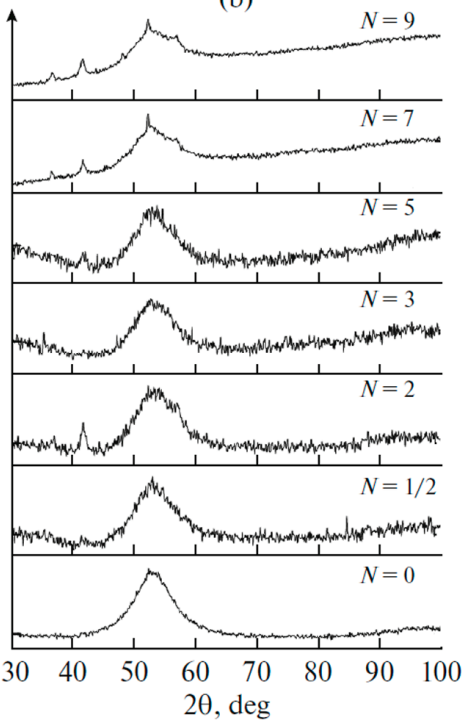

(c)

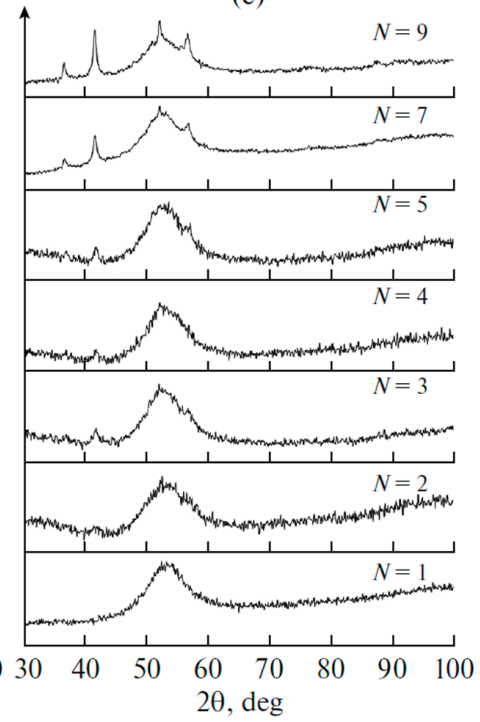

Figure 2. X-ray diffraction (XRD) patterns of multilayer AA samples subjected to high-pressure torsion (HPT): (a) $\mathrm{Fe}_{53.3} \mathrm{Ni}_{26.5} \mathrm{~B}_{20.2}$, (b) $\mathrm{Co}_{28.2} \mathrm{Fe}_{38.9} \mathrm{Cr}_{15.4} \mathrm{Si}_{0.3} \mathrm{~B}_{17.2}$ and (c) composite material.

Figure 2c shows the XRD patterns for the composites subjected to HPT. At $N=2$, the peak intensity corresponding to the first halo substantially decreases. With an increasing degree of deformation, the composites undergo a partial crystallization. The volume fraction of crystalline phase decreases at $N=4 ; V_{c r} \approx 18 \%, 9 \%$ and $19 \%$ at $N=3,4$ and 5 , respectively. Thus, up to $N=5$, we failed to transfer 
the alloys and the composites into a completely nanocrystalline state. More intense crystallization was detected at higher degrees of deformation $(N=7-9)$ (Figure 2).

To refine the phase transformations, and to identify the formed crystal structures, we supplemented the XRD data by TEM examination results. The TEM data confirmed that the $\mathrm{Fe}_{53.3} \mathrm{Ni}_{26.5} \mathrm{~B}_{20.2}$ and $\mathrm{Co}_{28.2} \mathrm{Fe}_{38.9} \mathrm{Cr}_{15.4} \mathrm{Si}_{0.3} \mathrm{~B}_{17.2} \mathrm{AA}$ remain completely amorphous at low degree of deformation.

First nanocrystals appear in the amorphous phase in the $\mathrm{Fe}_{53.3} \mathrm{Ni}_{26.5} \mathrm{~B}_{20.2} \mathrm{AA}$ at $\mathrm{N}=3$ at the edge of the disk samples (Figure 3a). Such crystals correspond to $\alpha$-Fe $(\operatorname{Im} 3 \mathrm{~m}, a=b=c=0.2857 \mathrm{~nm})$. At the late stages of deformation, the volume fraction of the crystalline phase substantially increases (Figure $3 b$ ), and the $\mathrm{Fe}_{2} \mathrm{~B}$ (I4/mcm, $a=b=0.5099 \mathrm{~nm}, c=0.4240 \mathrm{~nm}$ ) and FeB (Pnma, $a=0.4053 \mathrm{~nm}, b=0.5495 \mathrm{~nm}$, $c=0.2946 \mathrm{~nm}$ ) boride precipitates are also observed. The nanocrystallite size is $10-40 \mathrm{~nm}$.
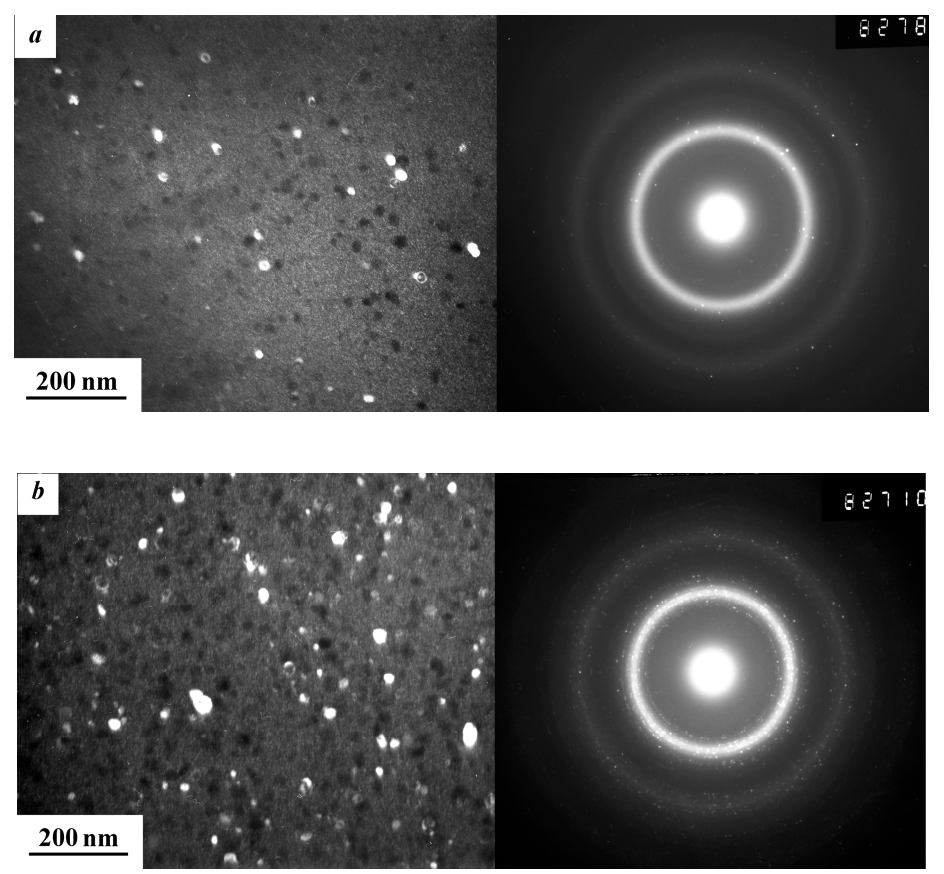

Figure 3. Dark-field images of the of $\mathrm{Fe}_{53.3} \mathrm{Ni}_{26.5} \mathrm{~B}_{20.2}$ AA structure subjected to HPT to $N=3$ (a) and $N=9$ (b) and the corresponding selected area electron diffraction (SAED) patterns.

The first evidences of crystallization in the $\mathrm{Co}_{28.2} \mathrm{Fe}_{38.9} \mathrm{Cr}_{15.4} \mathrm{Si}_{0.3} \mathrm{~B}_{17.2} \mathrm{AA}$ are observed at $N=2$; local signs are also observed at the edge of the samples (Figure 4). The extended and coarse-grained phases precipitated from the amorphous matrix were identified as $\alpha$-Fe with BCC crystal lattice (Figure 4a) and $\alpha$-Co with HCP lattice (Figure $4 b$ ).

With increasing degree of deformation $(N \geq 3), V_{c r}$ of fine crystalline phase in $\mathrm{Co}_{28.2} \mathrm{Fe}_{38.9} \mathrm{Cr}_{15.4} \mathrm{Si}_{0.3} \mathrm{~B}_{17.2} \mathrm{AA}$ increases from the center of the sample to its periphery. Deformation to $N \geq 7$ leads to the formation of homogeneous structure throughout the sample. The nanocrystal size (5-25 nm) in the $\mathrm{Co}_{28.2} \mathrm{Fe}_{38.9} \mathrm{Cr}_{15.4} \mathrm{Si}_{0.3} \mathrm{~B}_{17.2} \mathrm{AA}$ is unchanged upon deformation to $N=4-9$. The crystalline particles correspond to $\alpha-\mathrm{Co}\left(\mathrm{P}_{4} / \mathrm{mmc}(\mathrm{A} 3), a=b=0.2514 \mathrm{~nm}, c=0.4105 \mathrm{~nm}\right)$ and the $\mathrm{Fe}_{2} \mathrm{~B}$ and $\mathrm{FeB}$ borides. The deformation-induced composites prepared from the Fe-Ni-B and Co-Fe-Cr-Si-B AA layer-by-layer packets at $N=2$ exhibit the following specific feature, which is similar to that of the $\mathrm{Co}_{28.2} \mathrm{Fe}_{38.9} \mathrm{Cr}_{15.4} \mathrm{Si}_{0.3} \mathrm{~B}_{17.2} \mathrm{AA}$ : coarse-grained crystalline areas are observed at $1 / 2$ radius of the disk samples. Similar grains are formed in the case where the crystallization of the $\mathrm{Co}_{28.2} \mathrm{Fe}_{38.9} \mathrm{Cr}_{15.4} \mathrm{Si}_{0.3} \mathrm{~B}_{17.2} \mathrm{AA}$ occurs upon high-temperature annealing. 

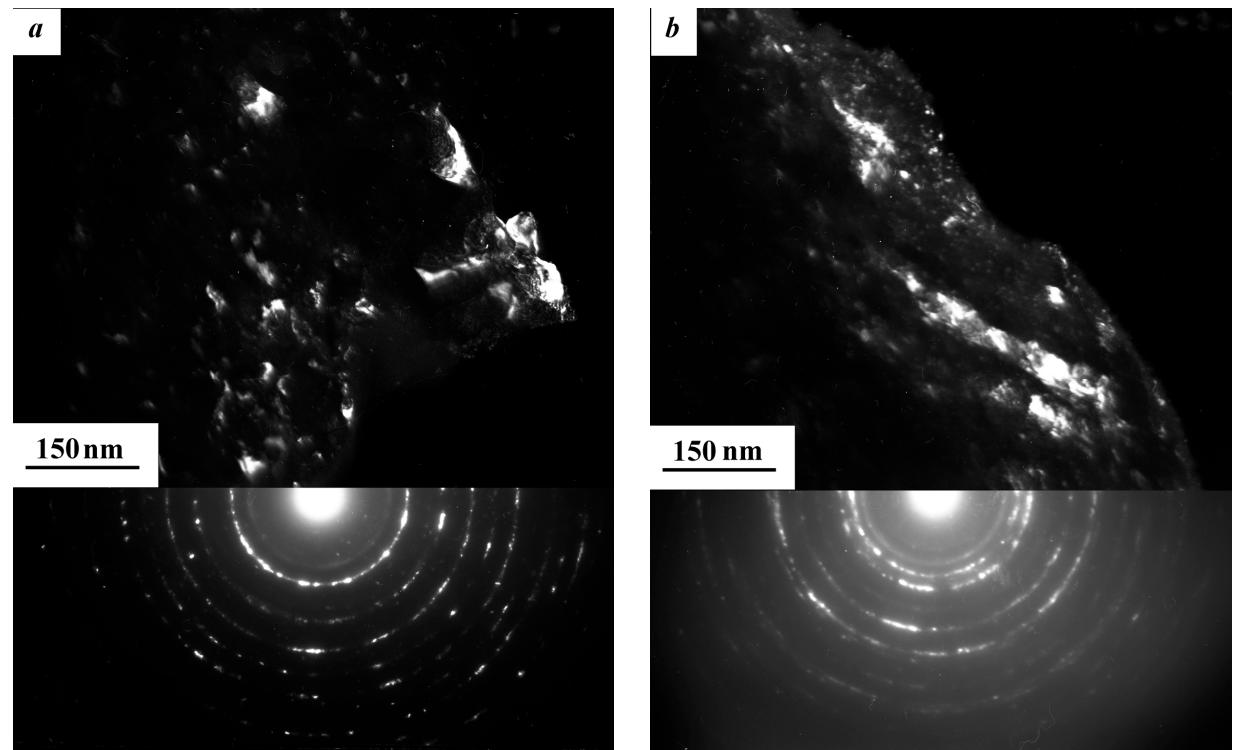

Figure 4. Dark-field images (TEM) and SAED patterns of $\alpha$-Fe (a) and $\alpha$-Co (b) in the $\mathrm{Co}_{28.2} \mathrm{Fe}_{38.9} \mathrm{Cr}_{15.4} \mathrm{Si}_{0.3} \mathrm{~B}_{17.2}$ AA subjected to HPT to $N=2$.

The shear bands (SB) observed in the composites formed by HPT up to $N=5$ exhibit the occurrence of highly localized plastic deformation (Figure 5). The SB become thinner with increasing degree of deformation.
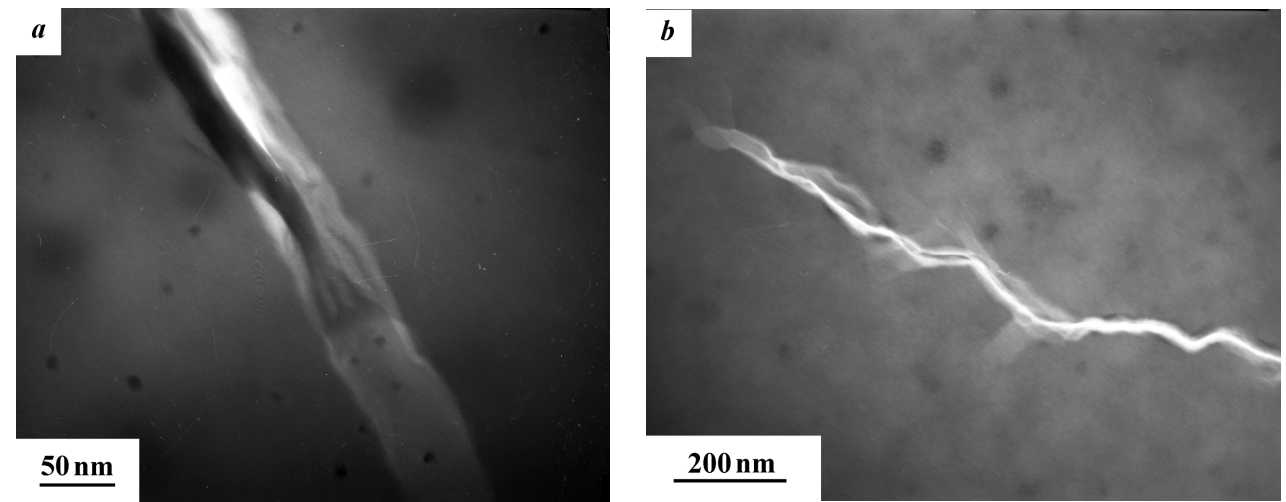

Figure 5. Shear bands in the composites formed from AA and subjected to HPT at $N=3$ (a) and $N=5(\mathbf{b})$.

Because of the small size of the nanocrystals formed upon HPT, the priority mechanisms of their interaction with SB (in accordance with the classification proposed in earlier works $[39,40]$ ) are suggested to be the "absorption" mechanism, at which moving SB absorbs nanoparticles without changing the motion path in the amorphous matrix (Figure 5a), and the "accommodation" mechanism, at which meeting of SB with an elastically stressed nanocrystal initiates the exit of one or several secondary SB to the amorphous matrix (Figure $5 b$ ).

In composites, an increase in the degree of deformation increases the volume fraction of the nanocrystalline phase and decreases the nanocrystal size (Figure 6). 

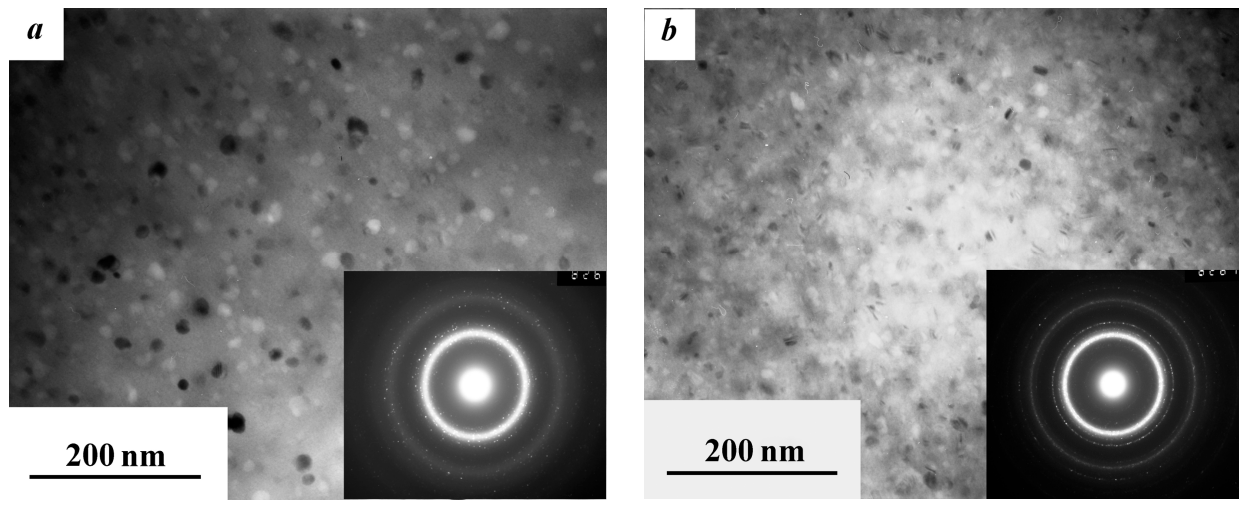

Figure 6. Bright-field images (TEM) of the composite structure after HPT to $N=3$ (a) and $N=7$ (b) and the corresponding SAED patterns.

At $N=9$, the composite passes into a completely nanocrystalline state (Figure 7). The precipitated phases were identified as BCC $\alpha-\mathrm{Fe}, \mathrm{HCP} \alpha-\mathrm{Co}$ and the $\mathrm{Fe}_{2} \mathrm{~B}$ and $\mathrm{Co}_{2} \mathrm{~B}$ borides.
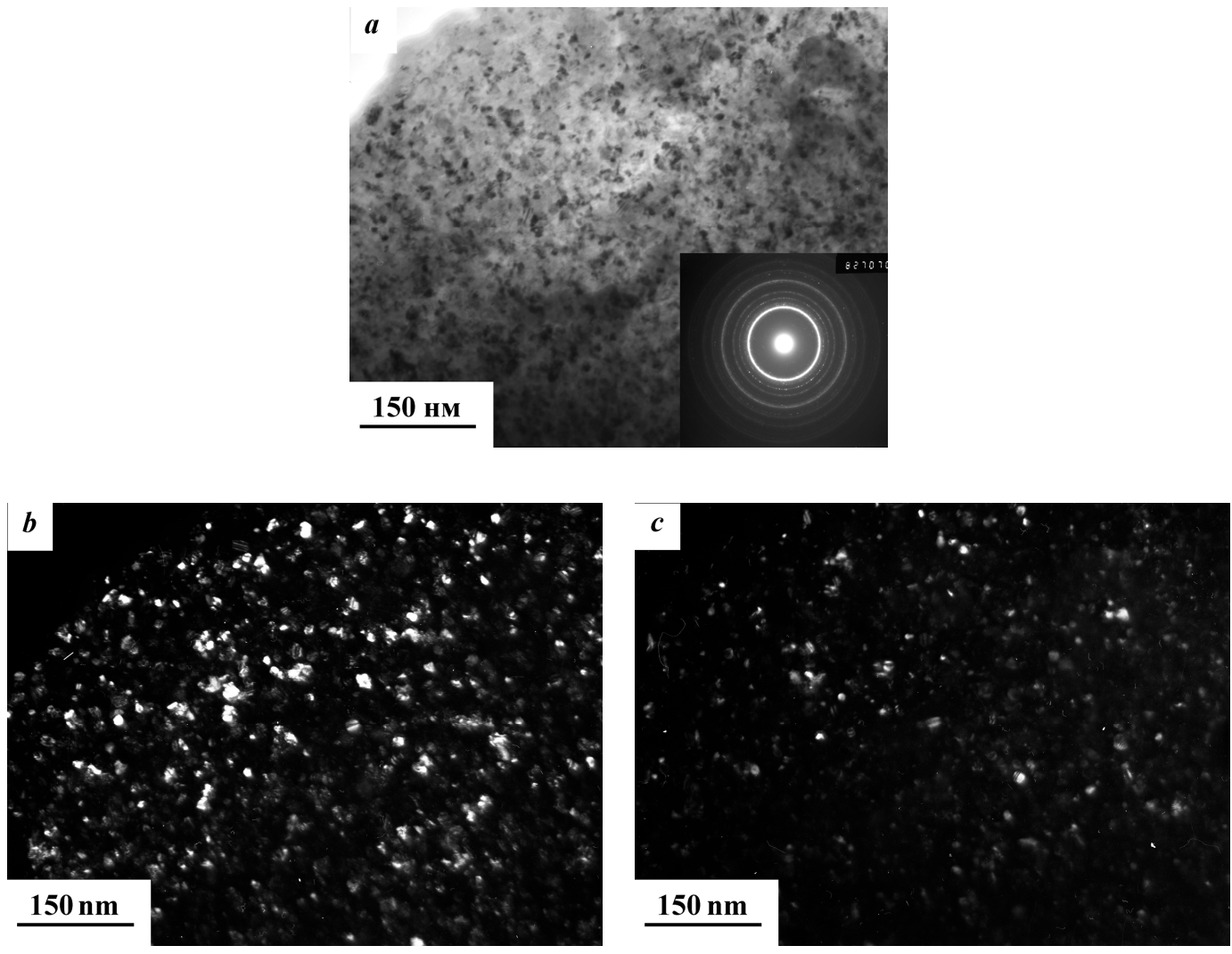

Figure 7. Bright-field image (TEM) of the composite after HPT to $N=9$ and the corresponding SAED pattern (a); and dark-field images (TEM) from the 1st (b) and 4th circles (c) of SAED pattern.

After small deformation to $N=2$, the microhardness $H V$ of the composite decreases by $16 \%$ (Figure 8). The minimum $H V$ of the $\mathrm{Fe}_{53.3} \mathrm{Ni}_{26.5} \mathrm{~B}_{20.2} \mathrm{AA}$ also corresponds to $N=2$. The microhardness of the $\mathrm{Co}_{28.2} \mathrm{Fe}_{38.9} \mathrm{Cr}_{15.4} \mathrm{Si}_{0.3} \mathrm{~B}_{17.2}$ AA decreases progressively over a wider strain range, and $H V_{\text {min }}$ is reached at $N=5$ (Figure 8). This effect can be related to the changes occurring upon HPT in the topological and chemical short-range orders before crystallization. Moreover, HPT initiates the formation of numerous SB in the amorphous matrix [41]. As is known, the presence of SB decreases 
the strength of AA and substantially facilitates plastic flow. We should also note an important role of migration processes and the redistribution of excess free volume regions near and inside SB.

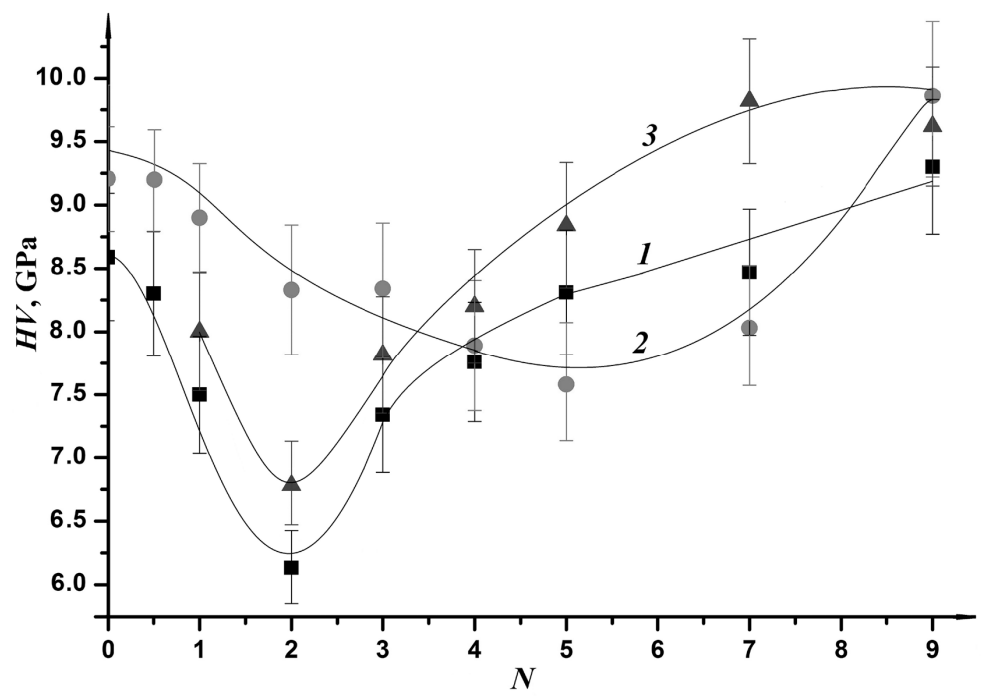

Figure 8. Microhardness of the materials as a function of number of revolutions upon HPT: 1- $\mathrm{Fe}_{53.3} \mathrm{Ni}_{26.5} \mathrm{~B}_{20.2} \mathrm{AA} ; 2-\mathrm{Co}_{28.2} \mathrm{Fe}_{38.9} \mathrm{Cr}_{15.4} \mathrm{Si}_{0.3} \mathrm{~B}_{17.2} \mathrm{AA} ; 3$-composite formed from different AA.

Figure 8 shows a very interesting and important effect related to the fact that the average microhardness (strength) of the composite obtained by HPT to $N>4$ (curve 3) exceeds microhardnesses of the individual components (curves 1 and 2), from which it is formed. If we follow the additivity rule, then microhardness of the composite should be between microhardnesses of its components. The observed synergic effect can be associated with the interdiffusion of the components of amorphous precursors upon HPT, and the formation of a new composition of amorphous or nanocrystalline state in the region of the interface between two amorphous layers. Such a new state can be anomalously hard in a fairly extended region of the contacting initial phases.

Preliminary studies demonstrated a plasticizing effect of heat treatment on the AA under consideration. The $K_{1 c}$ parameter of the $\mathrm{Fe}_{53.3} \mathrm{Ni}_{26.5} \mathrm{~B}_{20.2}$ and $\mathrm{Co}_{28.2} \mathrm{Fe}_{38.9} \mathrm{Cr}_{15.4} \mathrm{Si}_{0.3} \mathrm{~B}_{17.2}$ AA increases at temperatures ranging from $425^{\circ} \mathrm{C}$ to $445^{\circ} \mathrm{C}$ and from $425^{\circ} \mathrm{C}$ to $485^{\circ} \mathrm{C}$, respectively. With allowance for this result, the behavior of the $K_{1 c}$ parameter after HPT was studied for both AA separately and for deformation-induced composites based on them (Figure 9). For plastic deformation values up to $N=2$ revolutions, $K_{1 c}$ may depend on the orientation of layers. At high degrees of plastic deformation by HPT, intensive mixing of the layers occurs and the $K_{1 c}$ anisotropy will be leveled.

At low degrees of deformation, $K_{1 c}$ of the $\mathrm{Fe}_{53.3} \mathrm{Ni}_{26.5} \mathrm{~B}_{20.2} \mathrm{AA}, \mathrm{Co}_{28.2} \mathrm{Fe}_{38.9} \mathrm{Cr}_{15.4} \mathrm{Si}_{0.3} \mathrm{~B}_{17.2} \mathrm{AA}$, and the composite increases by $5.6 \%$ with a maximum at $N=2$, by $6 \%$ with a maximum at $N=3-4$, and by $7.3 \%$ with a maximum at $N=4$, respectively. Then, the crack resistance decreases for the composite and its individual components approximately by a factor of 1.3-1.4, relative to the initial levels. However, the comparison of $K_{1 c}$ at $N=7-9$ (Figure 9) and $K_{1 c}$ at high temperatures corresponding to the complete crystallization of the initially amorphous alloys shows that the crack resistance of the nanocrystalline structure obtained by SPD is higher than that of the coarse-grained structure initiated by annealing. In addition, even at high degrees of deformation $(N=7-9), K_{1 c}$ of the samples remain comparable with those of zirconia "ceramic steel" or laminar (layered) alumina-zirconia laminar composites, characterized by $K_{1 c}$ ranging between 9 and $15 \mathrm{MPa} \cdot \mathrm{m}^{1 / 2}$ [42]. 


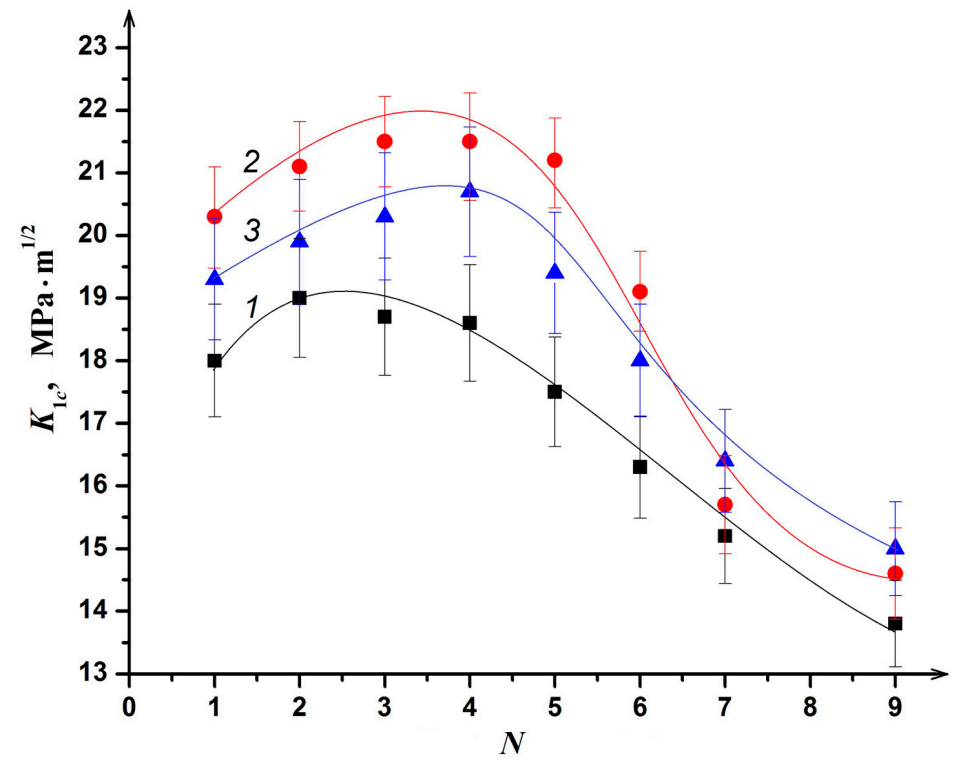

Figure 9. Crack resistance behavior of the materials subjected to HPT: 1- $\mathrm{Fe}_{53.3} \mathrm{Ni}_{26.5} \mathrm{~B}_{20.2} \mathrm{AA}$;

2- $\mathrm{Co}_{28.2} \mathrm{Fe}_{38.9} \mathrm{Cr}_{15.4} \mathrm{Si}_{0.3} \mathrm{~B}_{17.2} \mathrm{AA} ; 3$-composite.

The response of the magnetic characteristics of the materials after SPD has been studied. No significant effect of HPT on the specific saturation magnetization $\sigma_{s}$ was noted for the $\mathrm{Fe}_{53.3} \mathrm{Ni}_{26.5} \mathrm{~B}_{20.2}$ and $\mathrm{Co}_{28.2} \mathrm{Fe}_{38.9} \mathrm{Cr}_{15.4} \mathrm{Si}_{0.3} \mathrm{~B}_{17.2} \mathrm{AA}$, and for the composite based on the AA. The change in $\sigma_{s}$ does not exceed $2-3 \%$ in the entire strain range. Coercive force $H_{\mathrm{c}}$ as a more structure-sensitive characteristic nonmonotonically changes with increasing degree of deformation and exhibits a distinct maximum at $N=1$ (Figure 10). For the $\mathrm{Fe}_{53.3} \mathrm{Ni}_{26.5} \mathrm{~B}_{20.2}$ and $\mathrm{Co}_{28.2} \mathrm{Fe}_{38.9} \mathrm{Cr}_{15.4} \mathrm{Si}_{0.3} \mathrm{~B}_{17.2} \mathrm{AA}$, the maximum $H_{c}$ is higher than that of the initial state by a factor of 1.5-2. Further, $H_{c}$ decreases to the levels slightly exceeding the initial ones and becomes stabilized with the retention of the soft magnetic state of the alloys (Figure 10).

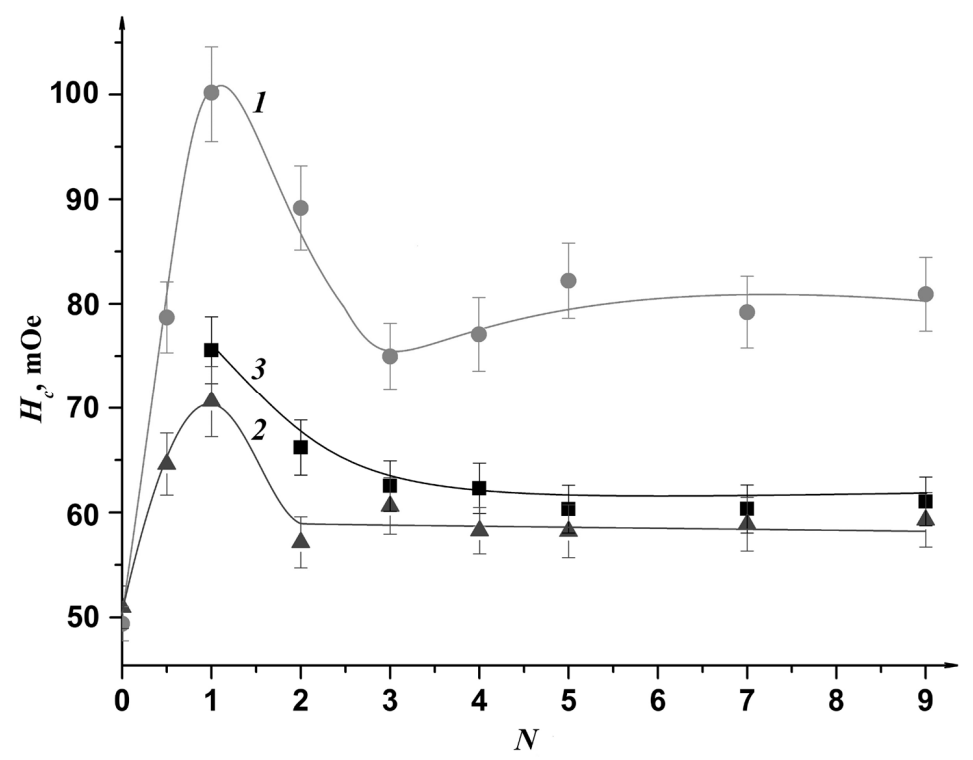

Figure 10. Coercive force as a function of the degree of deformation upon HPT: 1-Fe ${ }_{53.3} \mathrm{Ni}_{26.5} \mathrm{~B}_{20.2} \mathrm{AA}$; 2- $\mathrm{Co}_{28.2} \mathrm{Fe}_{38.9} \mathrm{Cr}_{15.4} \mathrm{Si}_{0.3} \mathrm{~B}_{17.2} \mathrm{AA} ; 3$-composite. 
The jumps of the coercive force at the initial stages of deformation can be associated with the processes of the delamination of the amorphous matrix, further clustering and, as a consequence, the accompanying changes in the exchange interaction between the ferromagnetic components. In addition, with increasing degree of deformation, the resulting SB can branch, due to the frontal formation of nanocrystals [23]. As a result, the additional local stresses generated in the structure of deformation-induced composites can affect the growth of the coercive force.

Thus, it is shown that SPD can be used as an effective method to create composites with improved properties by consolidating different AA ribbons.

\subsection{Amorphous-Nanocrystalline Composites Prepared by $\mathrm{HPT}$ of $\mathrm{Cu}-\mathrm{Nb}$ Nanolaminates}

Multilayer nanolaminates consisting of non-miscible or partially mutually soluble metals with nanometer (about $10 \mathrm{~nm}$ ) thickness of the layers of each component were first obtained by the method of magnetron deposition for the $\mathrm{Cu}-\mathrm{Nb}$ system [43]. Currently, such composites are obtained by MPR of copper and niobium sheets $[34,35,44,45]$. The $\mathrm{Cu}-\mathrm{Nb}$ nanolaminates are of interest for their special physical properties, such as high plasticity and electrical conductivity of copper combined with superconductivity of niobium.

The elasto-plastic properties (Young's modulus, amplitude-independent decremen, and stress-strain diagram in the range of microplastic deformation) of the $\mathrm{Cu}-\mathrm{Nb}$ nanolaminate were comprehensively studied in [46]. The analysis of the data on $E, \delta$ and $\sigma_{s}$ before and after the action of high hydrostatic pressure ( $1 \mathrm{GPa}$ ) allowed us to assume that the nanolaminate samples contain discontinuities, which can be formed at the interfaces between the $\mathrm{Cu}$ and $\mathrm{Nb}$ layers upon MPR.

$\mathrm{The} \mathrm{Cu} / \mathrm{Nb}$ nanolaminates under the effect of severe deformation were studied in more detail in [47]. The steady-state solubility of $\mathrm{Nb}$ in $\mathrm{Cu}$ and $\mathrm{Cu}$ in $\mathrm{Nb}$ were found to reach $\sim 1.5$ at. \% and $\sim 10$ at. $\%$, respectively, in near-boundary areas, but no phase transformations, including amorphization, occur in the nanolaminate.

The energy anisotropy of the interface in a system of non-miscible elements was first studied in [48-50] by the example of molecular-dynamics simulation of $\mathrm{Cu} / \mathrm{Nb}$ bicrystals. It was established that the mechanism of niobium dissolution in the copper matrix involves the formation of niobium clusters coherent with the matrix. Such coherent dissolution of non-miscible elements on the interface was noted in the literature for the $\mathrm{Cu}$-Fe system upon mechanical alloying of components [51].

The observed [48-50] phenomenon of niobium cluster dissolution near the $\mathrm{Cu} / \mathrm{Nb}$ interface of finite curvature is proposed as a physical explanation of the amorphization of such interface. Because of the lattice distortion by clusters, a sharp TEM image of the projection of close packed copper atom rows in the interface region disappears, and such regions are recognized as amorphous.

Our experiments have shown that the nanolaminates fabricated by MPR consist of about ten thousand $\mathrm{Cu}$ and $\mathrm{Nb}$ layers, which can vary in thickness from 100 to $300 \mathrm{~nm}$. The electron microscopic data confirm the nanolayering of the $\mathrm{Cu}-\mathrm{Nb}$ composite, as is illustrated in Figure 11. The layers have a wavy shape and sharp boundaries. In the image (Figure 11a) taken in backscattered electrons, the darker and lighter strips correspond to copper and niobium layers, respectively. Figure $11 \mathrm{~b}$ shows the EDS data on multilayer mapping of elemental composition.

A noticeable thinning of nanolaminate layers is observed after SPD by HPT. After HPT to a degree of deformation of $N=2$ turns, the layer thickness decreases approximately by a factor of two (Figure 12a), relative to the initial average layer thickness of $200 \mathrm{~nm}$ (Figure 11). At higher degree of deformation $(N=4)$, the effect of layer thinning is amplified, and their integrity is destroyed (Figure 12b). 

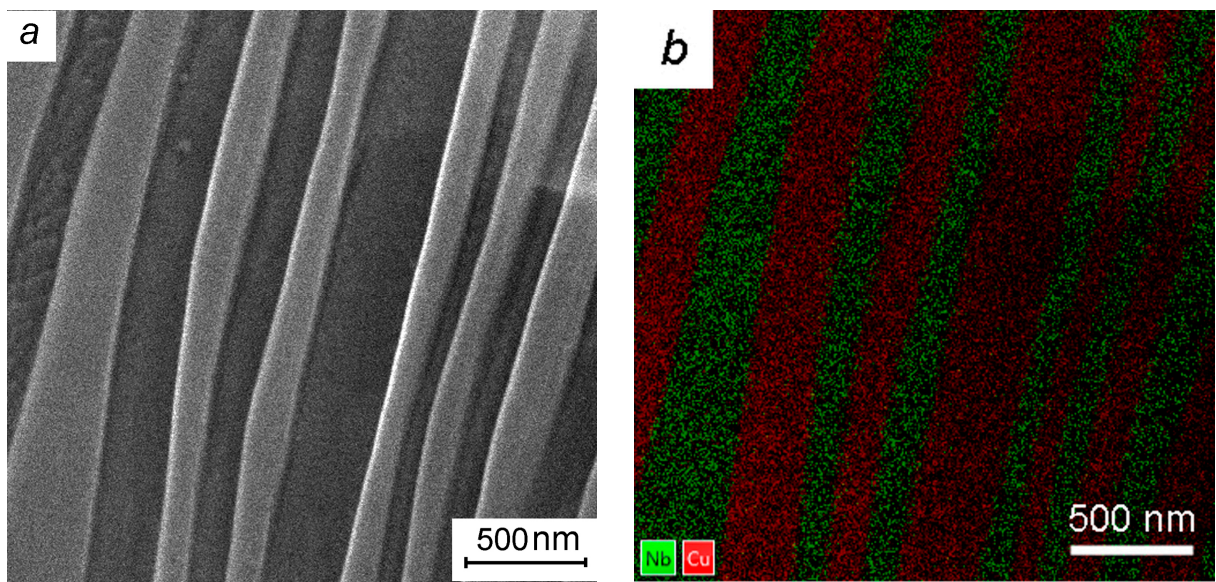

Figure 11. Structure of the cross section of $\mathrm{Cu}-\mathrm{Nb}$ composite as-fabricated by multiple pack rolling (MPR) $(N=0)$ : bright-field scanning transmission electron microscopy (BF-STEM) image (a), energy dispersive $\mathrm{X}$-ray spectroscopy (EDS) mapping (b).
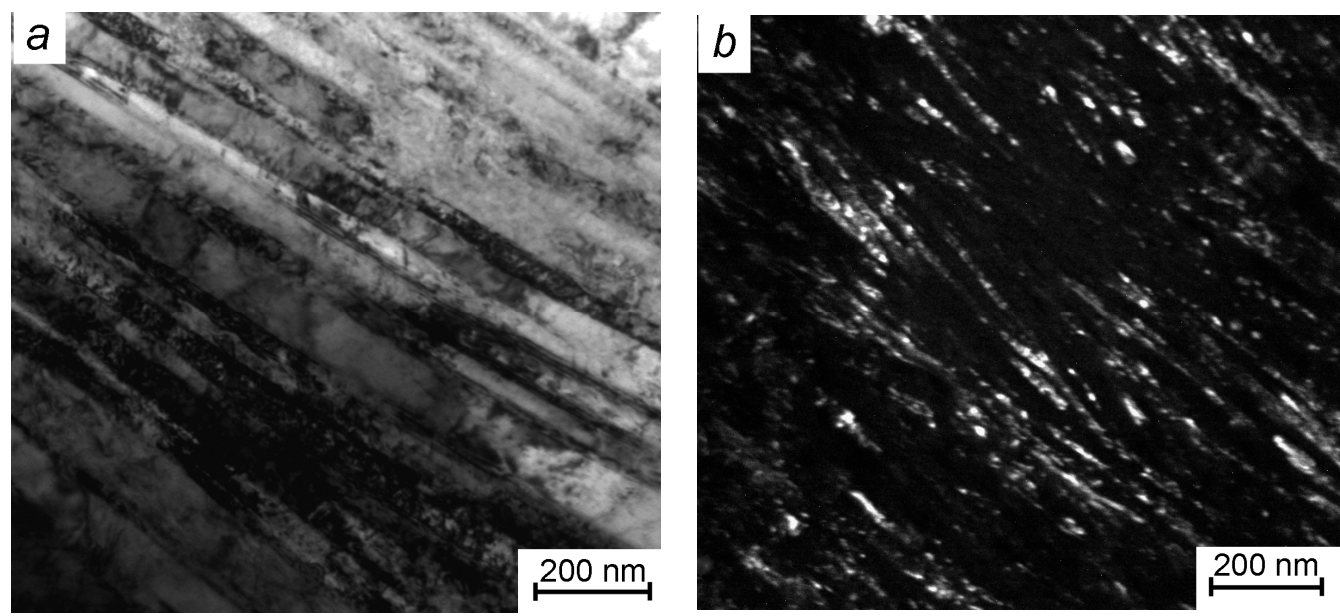

Figure 12. Planar microstructure of $\mathrm{Cu}-\mathrm{Nb}$ nanolaminate subjected to $\mathrm{HPT}: N=2$, bright-field TEM image (a); $N=4$, dark-field TEM image (b).

After HPT to $N=4$, the areas are observed, in which the layers are mixed, and the structure is substantially refined, but the grains retain their initial preferred orientation. The average size of crystalline grains decreases to tens of nanometers. The ring reflections of the FCC copper structure and the BCC niobium structure are clearly observed in the SAED pattern.

Table 1 shows the calculations of the true deformation value upon the HPT of $\mathrm{Cu}-\mathrm{Nb}$-nanolaminates in the middle of the sample radius, corresponding to the number of revolutions according to the formula:

$$
e \approx \ln \left(\frac{2 \pi r N h_{0}}{h^{2}}\right)
$$

where $r$ is the radius of the sample; $h_{0}$ is the initial thickness of the sample; $h$ is the final thickness of the sample; $N$ is the number of full revolutions of the movable anvil. 
Table 1. Geometric parameters of $\mathrm{Cu}-\mathrm{Nb}$ nanolaminates befor and after $\mathrm{HPT}$, calculated logarithmic true strain.

\begin{tabular}{ccc}
\hline Layer Thickness, $\mathbf{n m}$ & Number of Full Revolutions & Logarithmic True Strain, $\boldsymbol{e}$ \\
\hline 200 & 0 & - \\
180 & $1 / 2$ & 4.61 \\
130 & 1 & 5.42 \\
100 & 2 & 6.33 \\
50 & 3 & 6.54 \\
20 & 4 & 6.83 \\
\hline
\end{tabular}

If we conduct a comparative analysis of our Table 1 with data by Beyerlein I.J. et.al. [44], in our case, as a result of the HPT in the Bridgman anvils, to obtain nanolaminates with a layer thickness of $20 \mathrm{~nm}$, the logarithmic true strain $e=6.83$ is required, while accumulative roll bonding requires much large value: $e=11.51$. However, it should be noted that such a comparison seems incorrect to us. The fact is that in our studies, we subjected to HPT the finished $\mathrm{Cu}-\mathrm{Nb}$ composites obtained previously by the MPR method, which made it possible to reduce the layer thickness to $200 \mathrm{~nm}$ due to multi-stage accumulation of deformation. HPT is a subsequent and completely different SPD technology, which has a different loading MPR scheme, with a different stress condition of the sample, contributing to a further decrease in the layer thickness up to $20 \mathrm{~nm}$. Thus, we are dealing with two stages of material processing. The true deformations of each of them are different from each other and are not subject to simple summation.

Typical high-resolution (HR) TEM images of the atomic structure of the samples after HPT are shown in Figure 13a-c. Also, the fast Fourier transform (FFT) of the HR TEM image was calculated (Figure 13d). In addition to the crystalline grains of 10-30 $\mathrm{nm}$ in size, areas with a characteristic contrast are observed in Figure 13a,b, which unambiguously indicates the appearance of amorphous phase of up to $\sim 100 \mathrm{~nm}$ in size in the structure, after deformation by HPT to $N=4$. The volume fraction of such areas does not exceed $5-10 \%$. As a rule, they are elongated along the interface between $\mathrm{Cu}$ and $\mathrm{Nb}$ crystals. It can be seen that the crystalline regions 1,2,5,6 in Figure 13a,b according to the FFT analysis, have discrete point reflections from $\mathrm{Cu}$ or $\mathrm{Nb}$, while the amorphous regions 3,4,7,8 are continuous rings-a diffuse halo in FFT diffractograms (Figure 13d). Figure 13c demonstrates a periodic banded contrast of the crystalline grain, which is in the reflecting position. This contrast represents the projections of the $\{110\}$ planes onto the image plane. The direction of the incident electron beam coincides with the [111] direction. The BCC niobium and FCC copper structures have the same symmetry of atom projection onto the (111) plane. Therefore, it is difficult to determine what crystalline grain is in the observation field by the HR TEM image.

The X-ray mapping of element distributions $(\mathrm{Cu}, \mathrm{Nb})$ is carried out by the EDS method for the samples of $\mathrm{Cu}-\mathrm{Nb}$ nanolaminate subjected to HPT (Figure 14). We note that the structure of the sample after HPT is formed by oriented alternating $\mathrm{Cu}$ and $\mathrm{Nb}$ grains, which are clearly seen in the BSE image and element distribution maps (Figure 14). The transverse thickness of the elongated grains varies from 4 to $40 \mathrm{~nm}$. Thus, the mechanical treatment of the samples by HPT leads to the structure refinement almost by an order of magnitude. However, the general directionality (orientation) of the structure components is retained. Note that some niobium grains on the surface of the samples are enriched with oxygen.

In addition, substantial "mixing" is observed in copper and niobium layers. The boundaries of the layers lose their sharpness (Figure 15). As a consequence, regions with equal contents of the elements appear in the structure. The concept of "layer" is losing its original meaning. EDS mapping demonstrates the distribution of elements in the sample at a purely qualitative level. 

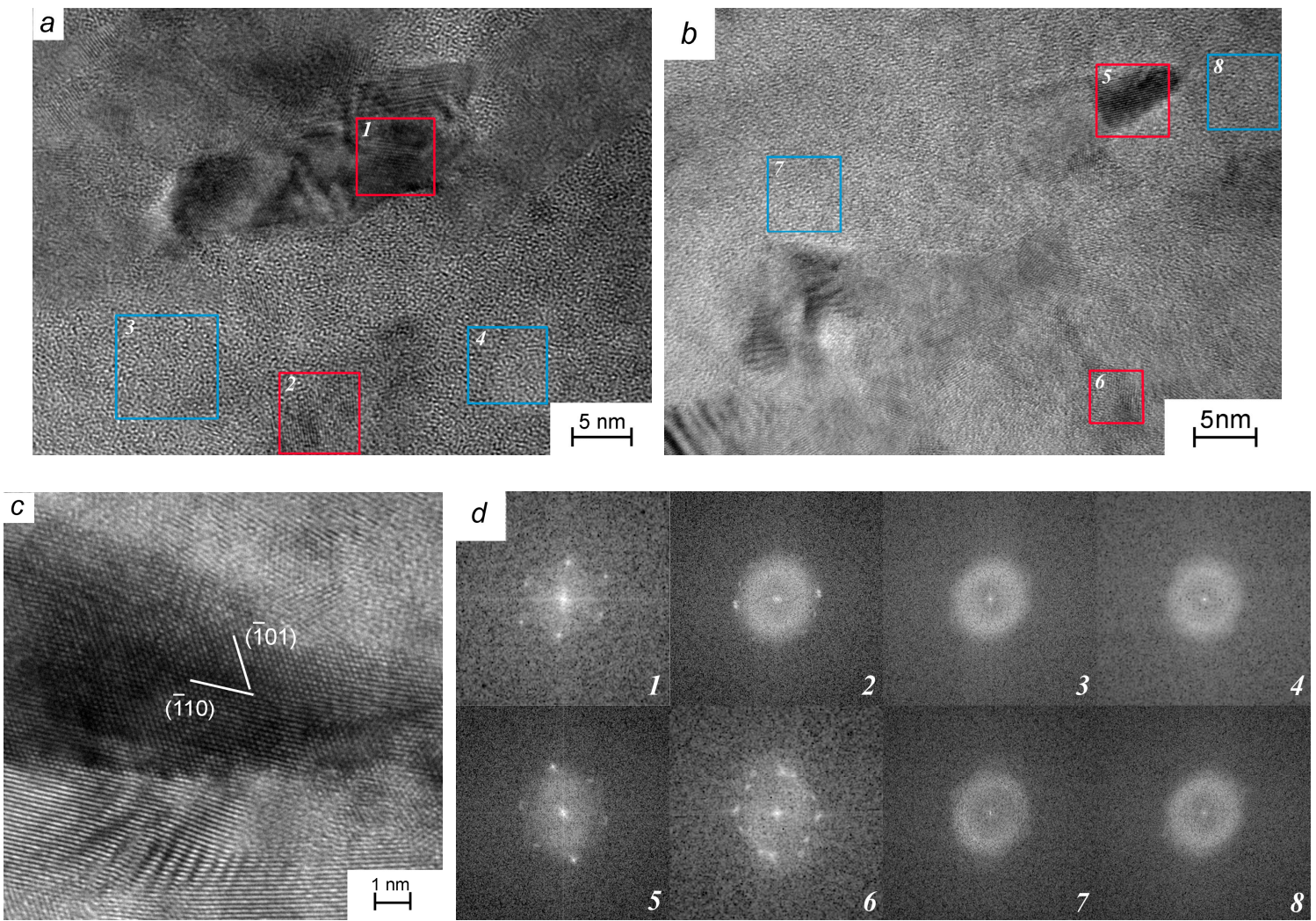

Figure 13. HR TEM images of the structure of $\mathrm{Cu}-\mathrm{Nb}$ nanolaminate after $\mathrm{HPT}$ to $\mathrm{N}=4(\mathbf{a}, \mathbf{b}, \mathbf{c})$ and fast Fourier transform (FFT) diffractograms (d) of the outlined areas 1-8 of (a),(b), respectively.
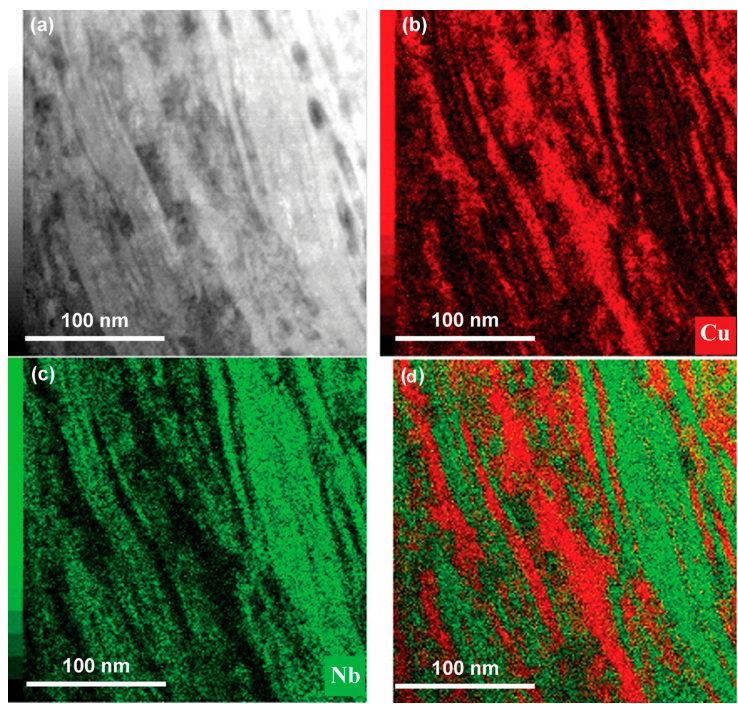

Figure 14. BF-STEM image (a) of the sample deformed by HPT to $N=4$ and X-ray element distribution maps: copper (b), niobium (c), superposition of $\mathrm{Cu}$ and $\mathrm{Nb}(\mathbf{d})$.

The sequence of structural-phase transformations in the $\mathrm{Cu}-\mathrm{Nb}$ nanolaminate after HPT was analyzed by XRD, along with TEM/STEM methods. The XRD spectra from the planes and the end faces of the samples before and after HPT in the Bridgman chamber are presented in Figure 16. The XDR intensities in Figure 16 are scaled linearly. With the aid of standard indexing procedures, we established 
that the experimental set of X-ray lines corresponds to copper (ICDD card No. 00-004-0836, Fm-3m, $a=0.3615 \mathrm{~nm}$ ) and niobium (ICDD card No. 00-034-0370, Im-3m, $a=0.3303 \mathrm{~nm}$ ).

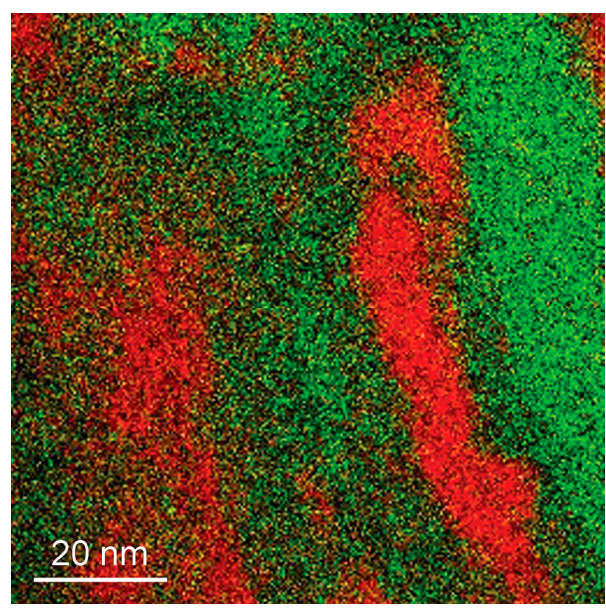

Figure 15. Fragment of the map of element distribution in the sample after HPT to $N=6: \mathrm{Cu}$ and $\mathrm{Nb}$ are displayed in red and green colors, respectively.
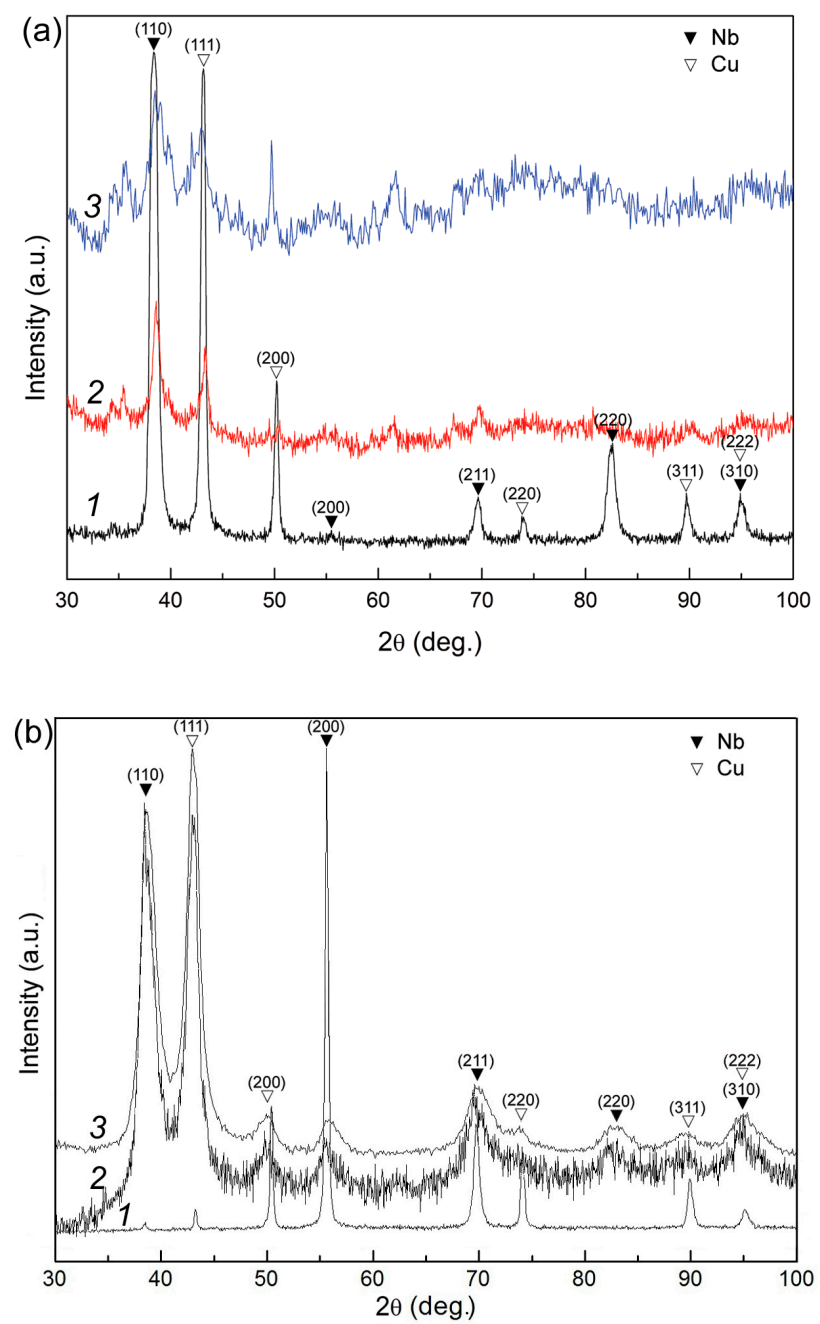

Figure 16. XRD spectra of the initial $\mathrm{Cu}-\mathrm{Nb}$ nanolaminate $1-N=0$ and after HPT to $2-N=2$ and $3-N=4$ : (a) plane of sample, (b) end face of sample. 
Comparing the profiles of the spectra, we see that the intensity of the X-ray maxima after deformation decreases. This fact can be associated with the intense fragmentation of grains and the increase of the defect density. In addition, some maxima are "blurred". This is a consequence of strain-induced amorphization processes beginning at $N=4$, which are also revealed by the TEM studies (Figure 13a,b). Thus, the accumulation of deformation is accompanied by the degradation of the nanolaminite structure of the samples: the regularity of the layer alternation is disrupted, the layers become fragmented and curved, and the $\mathrm{Cu} / \mathrm{Nb}$ system partially undergoes the transition from crystalline to amorphous state. As a prerequisite for the formation of a supersaturated solid solution during the HPT process, conditions can arise that are characterized by an inhomogeneous distribution of the components in the bulk of the material. Based on the fact that in the laminate there are areas with different concentrations of one of the components, this should partially change the lattice parameter and, accordingly, the position of the lines on the XRD spectra. The line will shift towards smaller angles if the volume is enriched in the second component. At the same time, the depletion of the remaining volume by this component causes a decrease in the parameter, and, therefore, should shift the diffraction line toward large angles. In a word, such heterogeneity is capable of causing some broadening of the lines of the XRD spectra. In Figure 16, the $\mathrm{Cu}(200)$ line shifts toward smaller angles by $\sim 0.5$ degrees $2 \theta$ with increasing strain during HPT. In the process of migration of the $\mathrm{Cu} / \mathrm{Nb}$ interphase boundary is possible to incorporate of nanolamellas of one metal into another with the subsequent formation of isolated monatomic clusters. The crystal structure was distorted in cluster and lamella regions, which could be perceived as amorphization of the interphase boundary in studies by the methods of high-resolution microscopy [48].

The peaks at 35-38 and 63-69 degrees $2 \theta$ in Figure 16a may belong to tungsten carbide. Their appearance on the XRD spectra is due to the fact that Bridgman anvils heads are made of it. Accordingly, at large degrees of deformation, traces of WC can be observed on the surface of the deformed samples. When comparing the results, Figure $16 \mathrm{~b}$ shows that when shooting at the end faces of the sample (at 35-38 and 63-69 degrees 20), no lines from the tungsten carbide phases are observed. A similar situation with the appearance of additional peaks in the $\mathrm{Cu}-\mathrm{Nb}$ XDR spectra was observed in [52].

The appearance of an amorphous phase in the near-interface areas was first experimentally established in our investigation by the methods of direct-resolution TEM (Figure 13a,b) and XRD (Figure 16). This confirms the hypothesis [48-50] on the possibility of the clustered structure of the regions containing simultaneously copper and niobium atoms. In a rather detailed scientific work [47], no amorphous phases have been detected in the $\mathrm{Cu}-\mathrm{Nb}$ nanolaminates after SPD, but nonequilibrium supersaturated solid solutions of $\mathrm{Cu}-\mathrm{Nb}$ (up to 1.5 at. \% Nb) and $\mathrm{Nb}-\mathrm{Cu}$ (up to 10 at. \% $\mathrm{Cu}$ ) have been observed. The discrepancy between our results and the results of [47] could be caused by the fact that, because of somewhat different conditions of SPD in the Bridgman chamber, the supersaturated solid solutions in our case are less thermodynamically stable and undergo phase transition from crystalline (solid solution of $\mathrm{Nb}-\mathrm{Cu}$ and/or $\mathrm{Cu}-\mathrm{Nb}$ ) to amorphous phase ( $\mathrm{Nb}-\mathrm{Cu}$ and/or $\mathrm{Cu}-\mathrm{Nb}$ ). It seems that, in our case, the following relation is satisfied:

$$
U_{s s}>U_{a p}
$$

where $U_{s s}$ and $U_{a p}$ are the free energies of nonequilibrium crystalline solid solutions and $\mathrm{Cu}-\mathrm{Nb}$ and $\mathrm{Nb}-\mathrm{Cu}$ amorphous phases, respectively. Relation (1) is fulfilled at concentrations of solid solutions above critical. Apparently, such supercritical concentrations of the dissolved component were achieved in our experiments, but were not achieved by the authors of [47].

We established the pattern of the Vickers hardness variations in the $\mathrm{Cu}-\mathrm{Nb}$ nanolaminate as a function of the degree of deformation (Figure 17). 


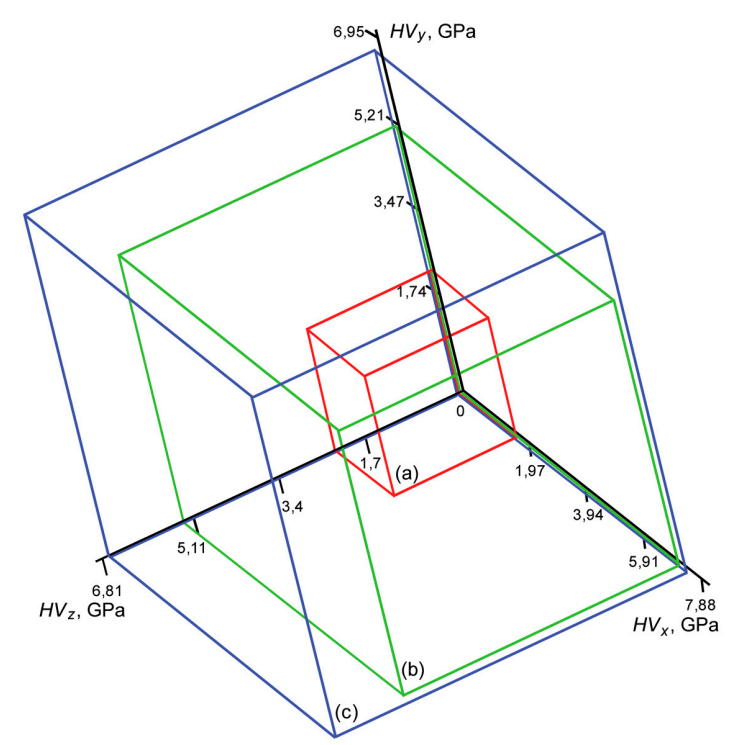

Figure 17. Behavior of microhardness $H V$ of the $\mathrm{Cu}-\mathrm{Nb}$ nanocomposites in three mutually orthogonal directions as a function of the degree of deformation: before HPT at $N=0$ (a); after HPT to $N=2$ (b) and $N=4(\mathbf{c})$, respectively.

The anisotropy of $H V$ is observed in the initial samples before HPT. The indentation results show that the microhardness of two mutually perpendicular ends is somewhat higher (see the $Y$ and $Z$ axes in Figure 17) than $H V$ of the planar surface of the disk samples (see the $X$ axis). Figure 17a shows that the $H V$ edges of red rectangular parallelepiped are unequal. As the degree of deformation increases, a significant growth in microhardness is observed in all directions (see green rectangular parallelepiped in Figure 17b). The maximum difference in the microhardness $H V$ on the surface (along the $X$ axis) and on the ends (along $Y$ and $Z$ axes) is observed at $N=2$. In other words, a strengthening surface effect of the nanolaminates was found after HPT to $N=2$. The transition from anisotropy to isotropy of microhardness (blue cube in Figure 17c with equal $H V$ edges) is observed after HPT to $N=4$.

Thus, we observe two stages of the strengthening of nanolaminates upon HPT. First, there is a noticeable increase in microhardness (strength) under conditions of remaining structural anisotropy caused by the initial plate-like shape of the structure constituents of the composite. Then, at the second stage, there is a transition to isotropic growth of $H V$, due to much more uniform volume distribution of $\mathrm{Cu}$ and $\mathrm{Nb}$ nanoparticles, which underwent significant transformations of size and shape (degradation of the nanolaminated structure) upon HPT. The jump-like increase in $H V$ is caused by complex changes in the $\mathrm{Cu}-\mathrm{Nb}$ nanolaminated structure as the degree of SPD increases, namely, the thinning of nanolayers, the appearance of regions of the amorphous phase and the amorphization-induced modification of the interphase interfaces of $\mathrm{Cu}$ and $\mathrm{Nb}$ nanocrystals.

\section{Conclusions}

(1) For the first time, deformation-induced composites from alternating Fe-Ni-B and Co-Fe-Cr-Si-B AA layers were obtained by their consolidation upon HPT. It was found that the average microhardness of the composite obtained by HPT to $N>4$ exceeds $H V$ of its individual AA components, from which it is formed.

(2) The degree of the structure refinement of the amorphous nanocrystalline composites obtained by SPD depends on the processing regime and on the nature of the starting materials. The HPT method allows one to obtain nanocrystals of up to $5-20 \mathrm{~nm}$ in size in amorphous matrix in the AA composites. In the $\mathrm{Cu}-\mathrm{Nb}$ nanolaminates, the gradual refinement of the nanocrystalline structure can be accompanied by local amorphization and the retention of the general orientation of the 
structure constituents. The fact that an amorphous state is formed in $\mathrm{Cu}-\mathrm{Nb}$ laminates during HPT requires further and more thorough investigation.

(3) The phenomenon of increase in ductility ( $K_{1 c}$ increases by $\sim 6 \%$ ) of amorphous-nanocrystalline composites obtained by HPT of the $\mathrm{Fe}_{53.3} \mathrm{Ni}_{26.5} \mathrm{~B}_{20.2}$ and $\mathrm{Co}_{28.2} \mathrm{Fe}_{38.9} \mathrm{Cr}_{15.4} \mathrm{Si}_{0.3} \mathrm{~B}_{17.2}$ AA ribbons is established. SPD allows one to obtain strain-induced composites with satisfactory fracture toughness in combination with high hardness and high soft magnetic characteristics.

(4) For the first time, the formation of regions with an amorphous structure directly related to interphase interfaces was experimentally found in $\mathrm{Cu}-\mathrm{Nb}$ nanolaminates by TEM and XRD methods after a high degree of SPD $(N=4)$.

(5) An increase in the degree of SPD by HPT increases strength of the $\mathrm{Cu}-\mathrm{Nb}$ nanolaminates by a factor of three. A two-stage transition from the anisotropy of microhardness in the initial state to the isotropy of $H V$ was detected at $N=4$. Surface strengthening of the $\mathrm{Cu}-\mathrm{Nb}$ nanolaminates is observed at $N=2$; the difference between $H V$ on the surface and in the volume is $29 \%$.

Author Contributions: Conceptualization and Methodology, A.G. and I.P.; software, I.P.; validation, A.G. and I.P.; formal analysis, I.P.; investigation, A.G. and I.P.; resources, A.G.; data curation, I.P.; writing-original draft preparation, I.P.; writing-review and editing, A.G. and I.P.; visualization, I.P.; supervision and project administration, A.G.; funding acquisition, I.P. All authors have read and agreed to the published version of the manuscript.

Funding: The reported study was funded by RFBR, project numbers 17-02-00402 and 20-08-00341.

Acknowledgments: The authors are grateful to their colleagues, Michael Karpov, Victor Vnukov, Dmitry Shtansky, Igor Shchetinin, Michael Gorshenkov, Elena Savchenko and Elena Blinova for long-term fruitful cooperation.

Conflicts of Interest: The authors declare no conflict of interest.

\section{References}

1. Matthews, F.L.; Rawlings, R.D. Composite Materials: Engineering and Science; CRS Press: Boca Raton, USA, 1999; ISBN 0-8493-0621-3.

2. Gibson, R.F. Principles of Composite Material Mechanics, 4th ed.; CRC Press: Boca Raton, USA, 2016; ISBN 978-1-4987-2072-4.

3. Strong, A.B. Fundamentals of Composites Manufacturing Materials, Methods and Applications, 2nd ed.; Society of Manufacturing Engineers: Dearborn, MI, USA, 2008; ISBN 978-0872638549.

4. Barnett, S.A. Deposition and Mechanical Properties of Superlattice Thin Films. In Physics of Thin Films. Mechanic and Dielectric Properties. Advances in Research and Development; Francombe, M.H., Vossen, J.A., Eds.; Academic Press: New York, NY, USA, 1993; Volume 17, pp. 1-77. ISBN 978-0-1253-3017-6.

5. Vepřek, S. The search for novel, superhard materials. J. Vac. Sci. Technol. A 1999, 17, 2401-2420. [CrossRef]

6. Hovsepian, P.E.; Lewis, D.B.; Münz, W.-D. Recent progress in large scale manufacturing of multilayer/superlattice hard coatings. Surf. Coat. Technol. 2000, 133, 166-175. [CrossRef]

7. Barnett, S.A.; Madan, A.; Kim, I.; Martin, K. Stability of nanometer-thick layers in hard coatings. MRS Bull. 2003, 28, 169-172. [CrossRef]

8. Chung, Y.-W.; Sproul, W.D. Superhard coating materials. MRS Bull. 2003, 28, 164-168. [CrossRef]

9. Münz, W.-D. Large-scale manufacturing of nanoscale multilayered hard coatings deposited by cathodic arc/unbalanced magnetron sputtering. MRS Bull. 2003, 28, 173-179. [CrossRef]

10. Abrosimova, G.E. Evolution of the structure of amorphous alloys. Phys.-Usp. 2011, 54, 1227-1242. [CrossRef]

11. Perrière, L.; Champion, Y. Phases distribution dependent strength in metallic glass-aluminium composites prepared by spark plasma sintering. Mater. Sci. Eng. A 2012, 548, 112-117. [CrossRef]

12. Wang, Y.; Li, J.; Hamza, A.V.; Barbee, T.W. Ductile crystalline-amorphous nanolaminates. Proc. Natl. Acad. Sci. USA 2007, 104, 11155-11160. [CrossRef]

13. Donohue, A.; Spaepen, F.; Hoagland, R.G.; Misra, A. Suppression of the shear band instability during plastic flow of nanometer-scale confined metallic glasses. Appl. Phys. Lett. 2007, 91, 241905. [CrossRef] 
14. Molokanov, V.V.; Chueva, T.R.; Umnov, P.P.; Simakov, S.V.; Shalygina, E.E. "Thick" amorphous wires in the $\mathrm{Fe}_{75} \mathrm{Si}_{10} \mathrm{~B}_{15}-\mathrm{Co}_{75} \mathrm{Si}_{10} \mathrm{~B}_{15}-\mathrm{Ni}_{75} \mathrm{Si}_{10} \mathrm{~B}_{15}$ system: Fabrication, structure, properties. Inorg. Mater. Appl. Res. 2016, 7, 643-647. [CrossRef]

15. Shalygina, E.E.; Umnova, N.V.; Umnov, P.P.; Molokanov, V.V.; Samsonova, V.V.; Shalygin, A.N.; Rozhnovskaya, A.A. Specific features of magnetic properties of "thick" microwires produced by the Ulitovsky-Taylor method. Phys. Solid State 2012, 54, 287-292. [CrossRef]

16. Shelyakov, A.; Sitnikov, N.; Saakyan, S.; Menushenkov, A.; Korneev, A. Study of two-way shape memory behavior of amorphous-crystalline TiNiCu melt-spun ribbon. Mater. Sci. Forum 2013, 738-739, 352-356. [CrossRef]

17. Glezer, A.M.; Manaenkov, S.E.; Permyakova, I.E.; Shurygina, N.A. Effect of nanocrystallization on the mechanical behavior of Fe-Ni-based amorphous alloys. Russ. Metal. 2011, 2011, 947-955. [CrossRef]

18. Glezer, A.M.; Permyakova, I.E.; Shurygina, N.A.; Rassadina, T.V. Structural features of crystallization and hardening of amorphous alloy in the Fe-Cr-B system. Inorg. Mater. Appl. Res. 2012, 3, 23-27. [CrossRef]

19. Shurygina, N.A.; Glezer, A.M.; Permyakova, I.E.; Blinova, E.N. Effect of nanocrystallization on the mechanical and magnetic properties of Finemet-type alloy $\left(\mathrm{Fe}_{78.5} \mathrm{Sil}_{3.5} \mathrm{~B}_{9} \mathrm{Nb}_{3} \mathrm{Cu}_{1}\right)$. Bull. Russ. Acad. Sci. Phys. 2012, 76, 44-50. [CrossRef]

20. Permyakova, I.E.; Glezer, A.M.; Ivanov, A.A.; Shelyakov, A.V. Application of laser design of amorphous FeCo-based alloys for the formation of amorphous-crystalline composites. Russ. Phys. J. 2016, 58, 1331-1338. [CrossRef]

21. Mudry, S.I.; Nykyruy, Y.S.; Kulyk, Y.O.; Stotsko, Z.A. Influence of pulse laser irradiation on structure and mechanical properties of amorphous $\mathrm{Fe}_{73.1} \mathrm{Nb}_{3} \mathrm{Cu}_{1.0} \mathrm{Si}_{15.5} \mathrm{~B}_{7.4}$ alloy. J. Achiev. Mater. Manufact. Eng. 2013, 61, 7-11.

22. Sitnikov, N.N.; Shelyakov, A.V.; Khabibullina, I.A.; Borodako, K.A. Two-way shape memory effect in rapidly quenched highly doped alloys of TiNi-TiCu system upon laser treatment. Bull. Russ. Acad. Sci. Phys. 2018, 82, 1136-1142. [CrossRef]

23. Glezer, A.M.; Permyakova, I.E. Melt-Quenched Nanocrystals; CRC Press: Boca Raton, FL, USA, 2013; ISBN 978-1-4665-9414-2.

24. Glezer, A.M.; Shurygina, N.A. Amorphous-Nanocrystalline Alloys; CRC Press: Boca Raton, FL, USA, 2017; ISBN 978-1-1385-0237-6.

25. Inoue, A.; Louzguine, D.V. Bulk Nanocrystalline and Nanocomposite Alloys Produced from Amorphous Phase. In Nanostructured Metals and Alloys. Processing, Microstructure, Mechanical Properties and Applications; Whang, S.H., Ed.; Woodhead Publishing Ltd.: Cambridge, UK, 2011; pp. 152-177. ISBN 978-1-84569-670-2.

26. Wilde, G. Bulk Nanostructured Materials from Amorphous Solids. In Bulk Nanostructured Materials; Zehetbauer, M.J., Zhu, Y.T., Eds.; Wiley-VCH. Verlag GmbH \& Co: Weinheim, Germany, 2009; pp. $293-310$. ISBN 978-3-5273-1524-6.

27. Glezer, A.M.; Kozlov, E.V.; Koneva, N.A.; Popova, N.A.; Kurzina, I.A. Plastic Deformation of Nanostructured Materials; CRC Press: Boca Raton, FL, USA, 2017; ISBN 978-1-1380-7789-8.

28. Valiev, R.Z.; Zhilyaev, A.P.; Langdon, T.G. Bulk Nanostructured Materials: Fundamentals and Applications; John Wiley \& Sons: Hoboken, NJ, USA, 2013; ISBN 978-1-118-09540-9.

29. Glezer, A.M. Creation principles of new-generation multifunctional structural materials. Phys.-Usp. 2012, 55, 522-529. [CrossRef]

30. Permyakova, I.E.; Blinova, E.N.; Shchetinin, I.V.; Savchenko, E.S. Amorphous-alloy-based composites prepared by high-pressure torsion. Russ. Metal. 2019, 2019, 994-1001. [CrossRef]

31. Permyakova, I.E.; Glezer, A.M.; Karpov, M.I.; Vnukov, V.I.; Shtansky, D.V.; Gorshenkov, M.V.; Shchetinin, I.V. Structural amorphization and mechanical properties of nanolaminates of the cooper-niobium system during high-pressure torsion. Russ. Phys. J. 2018, 61, 428-438. [CrossRef]

32. Glezer, A.M.; Permyakova, I.E.; Fedorov, V.A. Crack resistance and plasticity of amorphous alloys under microindentation. Bull. Russ. Acad. Sci. Phys. 2006, 70, 1599-1603.

33. Glezer, A.M.; Permyakova, I.E.; Manaenkov, S.E. Plasticizing effect in the transition from an amorphous state to a nanocrystalline state. Dokl. Phys. 2008, 53, 8-10. [CrossRef] 
34. Karpov, M.I.; Gnessin, B.A.; Vnukov, V.I.; Medved, N.V.; Volkov, K.G. Texture and Mechanical Properties of the Bulk Multilayered $\mathrm{Nb}-\mathrm{Cu}$ Composite. In Proceedings of the Intrernational Conference "Advanced Metallic Materials", Smolenice Castle, Slovakia, 5-7 November 2003; Slovak Academy of Sciences: Bratislava, Slovakia, 2003; pp. 141-143.

35. Karpov, M.I.; Vnukov, V.I.; Medved, N.V.; Volkov, K.G.; Khodos, I.I. Nanolaminate-Bulk Multilayered Nb-Cu Composite: Technology, Structure, Properties. In Proceedings of the 15-th International Plansee-Seminar, Reutte, Austria, 28 May-1 June 2001; Volume 4, pp. 97-107.

36. Yasuna, K.; Tarauchi, M.; Otsuki, A.; Ishihara, K.N.; Shingu, P.H. Bulk metallic multilayers produced by repeated press-rolling and their perpendicular magnetoresistance. J. App. Phys. 1997, 82, 2435-2438. [CrossRef]

37. Huang, B.; Ishihara, K.N.; Shingu, P.H. Bulk nano-scale Fe/Cu multilayers produced by repeated pressing-rolling and their magnetoresistance. J. Mater. Sci. Lett. 2000, 19, 1763-1765. [CrossRef]

38. Shtansky, D.V.; Kaneko, K.; Ikuhara, Y.; Levashov, E.A. Characterization of nanostructured multiphase Ti-Al-B-N thin films with extremely small grain size. Surf. Coat. Technol. 2001, 148, 206-215. [CrossRef]

39. Glezer, A.M.; Manaenkov, S.E.; Permyakova, I.E. Structural mechanisms of plastic deformation of amorphous alloys containing crystalline nanoparticles. Bull. Russ. Acad. Sci. Phys. 2007, 71, 1702-1707. [CrossRef]

40. Glezer, A.M.; Shurygina, N.A.; Zaichenko, S.G.; Permyakova, I.E. Interaction of deformation shear bands with nanoparticles in amorphous-nanocrystalline alloys. Russ. Metall. 2013, 2013, 235-244. [CrossRef]

41. Permyakova, I.E.; Glezer, A.M.; Grigorovich, K.V. Deformation behavior of amorphous Co-Fe-Cr-Si-B alloys in the initial stages of severe plastic deformation. Bull. Russ. Acad. Sci. Phys. 2014, 78, 996-1000. [CrossRef]

42. Gogotsi, G.A. Fracture resistance of ceramics: Base diagram and R-line. Strength Mater. 2006, 38, $261-270$. [CrossRef]

43. Schuller, I.K. New class of layered materials. Phys. Rev. Lett. 1980, 44, 1597-1600. [CrossRef]

44. Beyerlein, I.J.; Mara, N.A.; Carpenter, J.S.; Nizolek, T.; Mook, W.M.; Wynn, T.A.; McCabe, R.J.; Mayeur, J.R.; Kang, K.; Zheng, S.; et al. Interface-driven microstructure development and ultra-high strength of bulk nanostructured $\mathrm{Cu}-\mathrm{Nb}$ multilayers fabricated by severe plastic deformation. J. Mater. Res. 2013, 28, 1799-1812. [CrossRef]

45. Carpenter, J.S.; Vogel, S.C.; LeDonne, J.E.; Hammon, D.L.; Beyerlein, I.J.; Mara, N.A. Bulk texture evolution of $\mathrm{Cu}-\mathrm{Nb}$ nanolamellar composites during accumulative roll bonding. Acta Mater. 2012, 60, 1576-1586. [CrossRef]

46. Betekhtin, V.I.; Kolobov, Y.R.; Kardashev, B.K.; Golosov, E.V.; Narykova, M.V.; Kadomtsev, A.G.; Klimenko, D.N.; Karpov, M.I. Elasto-plastic properties of $\mathrm{Cu}-\mathrm{Nb}$ nanolaminate. Tech. Phys. Lett. 2012, 38, 144-146. [CrossRef]

47. Ekiz, E.H.; Lach, T.G.; Averback, R.S.; Mara, N.A.; Beyerlein, I.J.; Pouryazdan, M.; Hahn, H.; Bellon, P. Microstructural evolution of nanolayered $\mathrm{Cu}-\mathrm{Nb}$ composites subjected to high-pressure torsion. Acta Mater. 2014, 72, 178-191. [CrossRef]

48. Lipnitskii, A.G.; Nelasov, I.V.; Golosov, E.V.; Kolobov, Y.R.; Maradudin, D.N. A Molecular-dynamics simulation of grain-boundary diffusion of niobium and experimental investigation of its recrystallization in a niobium-copper system. Russ. Phys. J. 2013, 56, 330-337. [CrossRef]

49. Lipnitskii, A.G.; Nelasov, I.V.; Klimenko, D.N.; Mapadudin, D.N.; Kolobov, Y.P. Moleculardynamical simulation of multilayered $\mathrm{Cu} / \mathrm{Nb}$ composite. Materialovedenie 2009, 6, 7-10.

50. Nelasov, I.V.; Lipnitskii, A.G.; Kolobov, Y.R. Study of the evolution of the $\mathrm{Cu} / \mathrm{Nb}$ interphase boundary by the molecular dynamics method. Russ. Phys. J. 2009, 52, 1193-1198. [CrossRef]

51. Wei, S.; Oyanagi, H.; Wen, C.; Yang, Y.; Liu, W. Metastable structures of immiscible $\mathrm{Fe}_{x} \mathrm{Cu}_{100-x}$ system induced by mechanical alloying. J. Phys. Condens. Matter. 1997, 9, 11077-11083. [CrossRef]

52. Advani, A.H.; Thadhani, N.N. Shock-induced reaction synthesis of isomorphous (Cu-Ni) and immiscible (Cu-Nb) compounds. Metall. Mater. Trans. A 1999, 30, 1367-1379. [CrossRef]

(C) 2020 by the authors. Licensee MDPI, Basel, Switzerland. This article is an open access article distributed under the terms and conditions of the Creative Commons Attribution (CC BY) license (http://creativecommons.org/licenses/by/4.0/). 